\title{
Counsellor-in-Residence: Evaluation of a Residence-Based Initiative to Promote Student Mental Health
}

Tiffany A. Beks, Sharon L. Cairns, Serena L. Smygwaty, Olga A. L. Miranda Osorio, and Sheldon J. Hill

University of Calgary

\begin{abstract}
Many universities have implemented campus-based initiatives addressing students' mental health with the goal of promoting well-being. One such initiative is the newly developed Counsellor-in-Residence (CIR) program at the University of Calgary, which targets students' mental health by providing residence-based counselling services and mental health programming. In this process evaluation, students completed three waves of data collection conducted over the academic year. Each wave measured students' mental health literacy, using the Mental Health Literacy Scale (O’Connor \& Casey, 2015), and resiliency, using the Connor-Davidson Resilience Scale-25 (Connor \& Davidson, 2003). Males reported lower mental health literacy than females $(p<.001)$, and international students reported lower mental health literacy than domestic students $(p<.001)$. No differences in resilience levels were found between groups. These findings suggest that male and international students experience additional barriers to accessing campus-based mental health services. Implications for residence-based mental health programming that target male and international students are discussed.

\section{Résumé}

Certaines universités ont mis en place des initiatives pour répondre aux besoins de santé mentale et de bien-être de leurs étudiants. Le Counsellor-inResidence (CIR) de l'Université de Calgary, par exemple, offre des services de conseils en résidence et des programmes de santé mentale. Pour évaluer le CIR,
\end{abstract}


des étudiants ont participé à 3 séries de collecte de données qui mesuraient leurs connaissances face à la santé mentale ainsi que leur niveau de résilience. A partir de la Mental Health Literacy Scale (O'Connor \& Casey, 2015) et la Connor-Davidson Resilience Scale-25 (Connor \& Davidson, 2003), les hommes et les étudiants internationaux ont reçu des résultats inférieurs pour le MHLS comparativement aux filles ( $p<0,001)$. et aux étudiants canadiens $(p<0,001)$. Aucune différence au niveau de la résilience n'a été observée entre les groupes. Cet article discutera des répercussions sur les programmes de santé mentale en résidence pour les hommes et les étudiants internationaux.

\section{Introduction}

\section{Health}

A number of new experiences and challenges often accompany the transition to postsecondary education, such as leaving home for the first time, entering a more competitive academic environment, adapting to a new city or culture, and forming new relationships. As students progress through their university careers, they also undergo significant changes in identity formation, worldviews, and decision-making power (Arnett, 2000). For most students, the time spent at post-secondary institutions is embodied by new friendships, fond memories, and a sense of accomplishment. For other students, however, the time spent at post-secondary institutions is characterized by feelings of stress, anxiety, depression, and suicidal ideation (American College Health Association [ACHA], 2013; Heck et al., 2014).

Students attending post-secondary institutions may be at greater risk for poor mental health than the general population (Blanco et al., 2008). While there are many factors that increase the risk for developing mental health challenges, age appears to be a key contributor. Research indicates that nearly $50 \%$ of major mental illnesses present by adolescence and about 75\% present by age 24 (Potvin-Boucher, Szumilas, Sheikh, \& Kutcher, 2010). Furthermore, the average age of students attending post-secondary institutions in Canada is 23, with approximately 78\% of students being between the ages of 18 and 24 (ACHA, 2013). Evidently, the combination of age-related risk factors and the challenges posed by the university environment highlight the need for campus-based services that target mental health awareness, promotion, and help-seeking in Canadian post-secondary institutions (Heck et al., 2014).

\section{Factors that Contribute to Mental Illness in Post-Secondary Students}

Post-secondary students' risk of experiencing poor mental health is not only due to age but also to increased academic pressures to succeed and compete with other students, to manage financial burdens, and to accommodate shifts in lifestyle and diet. Additionally, changes in support networks, and most importantly, students' coping skills, may be insufficiently developed to adapt to the stress and adversity that accompanies postsecondary education (Coskun, Garipagaoglu, \& Tosun, 2014; DeRosier, Frank, Schwartz, \& Leary, 2013; Flatt, 2013). In 2013, a survey of more than 30 post-secondary institutions in Canada with over 30,000 respondents found that $67.6 \%$ of students reported experi- 
encing stress at above-average to extreme levels in the last 12 months (ACHA, 2013). Additionally, $89.3 \%$ of students felt overwhelmed by all they had to do, 86.9\% felt exhausted, and 56.5\% felt overwhelming anxiety in the last 12 months (ACHA, 2013). Unfortunately, many students enter post-secondary education lacking the skills to effectively cope with these feelings, and many turn to maladaptive coping mechanisms (e.g., drinking alcohol, using illicit substances) as opposed to adaptive coping mechanisms (e.g., engaging in stress management and self-care activities, seeking social support and/or mental health services) to manage them (Blanco et al., 2008; Kirsch et al., 2014).

\section{Promoting Resilience in Post-Secondary Students}

Given the risk of post-secondary students developing maladaptive coping skills, recent research has focused on discerning ways of replacing these skills with more adaptive ones, with the ultimate goal of increasing student resilience (e.g., DeRosier et al., 2013; Hartley, 2012; Pritchard, Wilson, \& Yamnitz, 2007). As it pertains to post-secondary students, resilience refers to the overarching ability to adapt flexibly and positively to stressful circumstances and to persevere in the face of adversity (e.g., finishing a course despite failing a midterm, pursuing new friendships despite missing old friends) (Connor \& Davidson, 2003; DeRosier et al., 2013).

In a study examining the factors that contribute to post-secondary student resilience, DeRosier, Frank, Schwartz, and Leary (2013) found that positive problem-solving skills and cognitive styles (e.g., strong emotion regulation skills; positive, optimistic thoughts about oneself and the future), positive social relationships, and regular engagement in self-care behaviours were the most powerful predictors of student resilience, even after controlling for levels of stress and adversity. Furthermore, they found that students with higher resilience were better able to cope with the demands of post-secondary education and exhibited more positive mental health and well-being. A longitudinal study by Pritchard, Wilson, and Yamnitz (2007) also found that first-year students who were more optimistic about themselves and the future at the beginning of the school year were less likely to use alcohol as a coping mechanism and to experience physical ailments and negative moods (i.e., anxiety, depression, and fatigue) than their less optimistic counterparts at the end of the year.

A number of cross-sectional and longitudinal studies have yielded similar findings, linking resilience to student well-being. For instance, Klibert and colleagues (2014) found that undergraduate students' self-reported resilience partially mediated relations between perfectionism and psychological distress (i.e., students who were both perfectionistic and resilient were much less likely to experience anxiety and depression than students who were perfectionistic and non-resilient). Similarly, Johnson, Taasoobshirazi, Kestler, and Cordova (2015) found that undergraduate students' self-reported resilience directly influenced adaptive coping strategy use, which in turn, directly influenced academic achievement. Evidently, if post-secondary institutions are to make large-scale improvements in student mental health and well-being, initiatives directed at enhancing student mental health should focus on improving student resilience through the provision of services that target (a) the promotion of hope, optimism, and positive coping skills and cognitive patterns; (b) health-promoting behaviours and stress reduction; and (c) social connectedness and community (Johnson et al., 2015; Klibert et al., 2014). 


\section{Promoting Mental Health Literacy in Post-Secondary Students}

Canadian post-secondary institutions are highly aware of the need to support and promote student resilience, and most offer a range of counselling services and other mental health programming to accomplish this goal (Heck et al., 2014). Despite the clear need and presence of on-campus mental health services, however, many students fail to utilize them (Eisenberg, Golberstein, \& Gollust, 2007). Eisenberg, Golberstein, and Gollust (2007) surveyed a random sample of 2,785 university students regarding their awareness and use of campus-based mental health services. Their results indicated that the anywhere from $37 \%$ to $84 \%$ of students experiencing mental distress did not seek out services due to a lack of perceived need, lack of awareness of services, and skepticism regarding treatment effectiveness. In contrast, Yorgason, Linville, and Zitzman (2008) found that students who were experiencing mental distress were more likely to be aware of campusbased mental health services than students who were not experiencing mental distress, yet a high proportion still chose not to use them.

What factors affect students' decisions to seek out mental-health services and supports? It appears that negative perceptions of seeking and attending mental health services (i.e., stigma) play the most powerful role in preventing students from utilizing on-campus services, with students not accessing mental health services because they are worried about what others may think and/or because of their own negative beliefs and attitudes toward mental illness (Eisenberg, Downs, Golberstein, \& Zivin, 2009; Eisenberg, Hunt, Speer, \& Zivin, 2011). The stigma literature makes an important distinction between two forms of stigma. Personal stigma refers to personally held negative attitudes and prejudice toward mental illness, whereas public stigma denotes societal negative attitudes and prejudice toward mental illness (Eisenberg, Downs, Golberstein, \& Zivin, 2009). To highlight the relative influence of these two forms of stigma, Eisenberg, Downs, Golberstein, and Zivin (2009) surveyed 5,555 undergraduate and graduate students across the United States and found that public stigma as well as personal stigma were highly prevalent on postsecondary campuses. Interestingly, however, only personal stigma beliefs were found to be negatively related to help-seeking behaviour, suggesting that personal stigma and poor mental health literacy (i.e., lack of awareness and understanding of mental illness, poor recognition of mental illness symptoms) played the strongest role in predicting students' mental health service use.

These findings were further supported by a review conducted by Gulliver, Griffiths, and Christensen (2010). These authors found that perceived personal stigma and embarrassment, poor mental health literacy, and a preference for self-reliance were the most prominent barriers to mental health help-seeking behaviour in adolescents and early adults. Eisenberg, Hunt, Speer, and Zivin (2011) also found that students preferred to deal with their issues themselves rather than seek out professional help. Finally, other research has identified lack of time and/or lack of awareness of service availability as additional barriers to service access (Robinson, Jubenville, Renny, \& Cairns, 2016). Based on these findings, a lack of mental health literacy, a preference for self-reliance, and a lack of time and knowledge of service availability constitute the biggest barriers to students' help-seeking behaviour on university campuses. 
The relationship between resilience and help-seeking for mental well-being has been largely overlooked in the literature. A study by Beatie, Stewart, and Walker (2016) examined factors that influence mental health help-seeking behaviour, including a factor that they described as psychological fortitude, a concept similar to resilience. The results showed that fortitude was not a significant predictor for help-seeking behaviour. As such, resilience may facilitate students' help-seeking in that it serves as a protective factor to cope with experiences in a healthy manner; however, future research is needed to clarify and determine whether a true relationship exists between these two constructs.

The present evaluation seeks to examine whether resilience and mental health literacy vary over the course of the academic year in conjunction with a newly piloted residencebased mental health program (i.e., Counsellor-in-Residence). This evaluation also seeks to explore whether resilience and mental health literacy vary based on student characteristics, and whether important, previously unaddressed barriers to seeking and accessing residence-based counselling services exist. Given the empirical link between resilience and well-being, and mental health literacy and help-seeking, respectively, examining temporal changes and group differences in resilience and mental health literacy could highlight possible pathways to enhancing help-seeking and accessing behaviours among an increasingly diverse residence-based student population.

\section{The Counsellor-in-Residence Program}

The provision of on-campus mental health services that target factors empirically related to service access and utilization, as well as the need to improve mental health itself is the responsibility of the institution. This is evidenced by the fact that every post-secondary institution in Alberta offers some form of mental health support (Heck et al., 2014). These services are often available to all students attending the institution, but university administration face different challenges and may have additional policies and procedures for students who attend the institution and live on-campus. In a recent study, Goh and Chiu (2009) proposed that services should include broad clinical care, an open-door policy, and strict confidentiality agreements. They also proposed that on-campus services should have transparent advertising of the services offered and what they include, should be subsidized by the government and the university, and should include open communication with other university departments. According to Goh and Chiu (2009), services should offer counselling, intervention programs, and educational seminars on substance use.

Post-secondary residence departments strive to create communities that are supportive and have the capacity to refer students to resources on-campus. Living on-campus allows for more interaction and support from university staff, specifically from student residence staff living with their peers; this, in turn, leads to an increase in the level and complexity of the training provided to residence student staff members with regards to identifying mental health issues, offering support, and referring students to campus resources (Harrison, 2013). However, little research exists on how students living on campus residences are accessing mental health services and how institutions can best support their mental health needs.

Residence Services at the University of Calgary, in collaboration with the Wellness Centre, began the Counsellor-in-Residence (CIR) program with the intention of increasing the connection between residence students and on-campus mental health resources. 
The program has two main objectives: offering flexible, accessible counselling services within the residence complex, and offering educational, skill-building programming in residence specific to mental health. Structured in three phases, coinciding with three successive academic years, the goal of the program is to increase students' knowledge of mental health, coping strategies, and resources on campus, as well as normalize the use of mental health services.

The first phase of the CIR program focuses on administrative and operational logistics, creating a basic awareness of the program, and establishing a baseline of students' perceptions around counselling and mental health. It also focuses on assessing residence students' needs and identifying topics of interest. The second phase focuses on increasing program awareness through intentional marketing channels and developing a structure of events that will be offered under the CIR umbrella. The third phase carries on with the goals of the first two phases and focuses on assessing successes and challenges of the program itself, as well as exploring opportunities for future funding through a thorough analysis of the program.

The first phase of the CIR program was implemented in the 2015/2016 academic year, and focused strongly on establishing the basic needs of the program, such as implementation, marketing, and content and delivery of educational materials. The counselling component of the program was available as of September 2015, with three Wellness Centre professionals available and working in residence: one student support advisor focusing on student connections and two psychologists serving as counsellors. Posters were created to inform students of the new program and included information on how to connect with the student support advisor.

Details of the program purpose as well as information regarding service access was disseminated on the Residence Services website, and all student staff members were informed of the program during their yearly training in August. All staff were asked to promote the program and CIR events in their communities, as well as make appropriate referrals to the support advisor for students seeking counselling. Understanding that student staff in residence can deal with high-stress situations, student staff were also encouraged to make use of the service as needed.

The student support advisor acted as the face of the program, and offered intakes and case management to students. While the counselling support was available to students from the beginning of the program, students' use of the service was predicted to be minimal based on a similar program implemented in previous years. However, the program showed significant success, with students and parents requesting information on how to access the service, and counsellors seeing students on a regular basis; in October, 18 out of 31 appointments available were booked by students. In January, four students contacted the CIR email requesting an appointment within a few hours of each other, and some students that started counselling in residence eventually continued their appointments at the Wellness Centre, opening spaces for other students seeking support within residence. Importantly, these findings held true despite an interruption in marketing due to the support advisor leaving the position mid-way through the year (mid-October through January) and not being replaced until early February.

The first year of implementation of the CIR highlighted the need for evaluating residence students' preferences and needs to inform future programming. Program offerings 
were designed and allocated based on resource availability. Posters were created for each program event, and information for both the student support advisor and new events were promoted in a biweekly email newsletter distributed to all residence students. Programs such as a six-week mindfulness and a seven-week happiness basics workshop were planned yet not implemented due to low student interest. A one-hour procrastination workshop and a stress management workshop were offered, but were also met with low attendance. While attendance to CIR programs was low in the first year of its implementation, it is worth noting that the educational aspects of the program were not a priority in the first phase and, as such, no curriculum or structure was prepared regarding event programming for the year.

\section{Need for the Current Evaluation}

According to Heck et al. (2014), program evaluations of post-secondary mental health services are undertaken infrequently, despite their important role in informing service design, implementation, and effectiveness. To date, no formal evaluations of the CIR program have been carried out at the $\mathrm{U}$ of $\mathrm{C}$ and thus, the level of mental health literacy and resilience among residence-based students remains unknown to program developers and upper administration. Given the important role of mental health literacy (Eisenberg, Downs, Golberstein, \& Zivin, 2009) and resilience (Johnson et al., 2015) in student mental health, and the CIR program objective to promote these qualities in students, it is particularly useful for program developers to gain an understanding of the level and nature of mental health literacy and resilience in the target population. Furthermore, it is particularly important that program developers understand how mental health literacy and resilience change over the course of the academic term and whether differences emerge between subpopulations within the residence-based student community.

As a newly piloted program, Residence Life Coordinators, in consultation with the Wellness Centre (in particular, counselling services), identified the need for baseline data on mental health literacy and resilience among residence students in order to inform future program delivery and implementation. As such, a process evaluation was undertaken to explore and monitor the self-reported mental health literacy, resilience, and needs of residence students, as well as their actual and projected receptiveness to CIR programming. According to Saunders, Evans, and Joshi (2005), a process evaluation is a form of evaluation that serves to monitor and maintain a record of program implementation, and facilitates understanding of the relationship between specific elements of a program and its outcomes. An exploratory evaluation of this nature was deemed the most effective and pragmatic of methods for meeting the needs identified by program developers. With these important considerations in mind, the current evaluation sought to answer the following questions:

- How do levels of mental health literacy and resilience present and change over the academic term, and by subpopulation, among students living in $\mathrm{U}$ of $\mathrm{C}$ residences?

- How willing are $\mathrm{U}$ of $\mathrm{C}$ students to seek residence-based counselling services?

- What are the perceived barriers to engaging with CIR programming identified by U of $\mathrm{C}$ residence students? 


\section{Methods}

\section{Participants}

This process evaluation study received ethical approval from the University of Calgary Conjoint Faculties Research Ethics Board. Approximately 2,400 undergraduate and graduate students residing in on-campus housing were invited to participate. From this population, 354 students participated in the three surveys administered between October 2015 and April 2016, resulting in response rates ranging from $3 \%$ to $7 \%$. After each data collection wave, respondents had the option to enter into a draw to win one of two prizes valued at approximately $\$ 100$. Table 1 shows the demographic characteristics of the sample, which is representative of the larger residence population from which it is drawn in terms of age, level of study, and student status.

Table 1. Demographic Characteristics of Evaluation Respondents as a Percentage of the Sample

Characteristic $\quad(n=354)$

Gender

Male

Female

64.4

Transgender

Gender Fluid

Age

Under 20

25-29

10.2

$30-34$

2.0

35-39

1.7

40-44

0.3

Level of Study

Undergraduate $\quad 80.3$

$\begin{array}{ll}\text { Graduate } & 19.7\end{array}$

Year in Program

1

42.3

2

22.7

3

15.9

4

13.1

$5^{+}$

6.0

Student Status

International $\quad 20.9$

Domestic $\quad 78.5$

Unspecified $\quad 0.6$




\section{Measures}

Three separate surveys were developed to correspond to each of the three evaluation time intervals. Each survey consisted of 13 demographic questions (e.g., area of study, ethnicity, gender), the Mental Health Literacy Scale (MHLS; O'Connor \& Casey, 2015), the Connor-Davidson Resilience Scale-25 (CD-RISC-25; Connor \& Davidson, 2003), and seven concluding evaluator-constructed questions regarding students' experiences accessing and using CIR programming.

The MHLS is a 35-item scale which measures the following attributes: (a) ability to recognize specific mental health disorders, (b) knowledge of how to seek mental health information, (c) awareness of risk factors and causes, (d) knowledge of self-treatments, (e) awareness of professional help available, and (f) attitudes that foster recognition of symptoms and appropriate help-seeking behaviours (O'Connor \& Casey, 2015). The MHLS demonstrates good internal reliability $(\alpha=.79)$ and good construct validity (O'Connor \& Casey, 2015). Scores range from 35 to 160 , with higher scores reflecting higher mental health literacy. In the current study, Cronbach's alpha ranged between $\alpha=.70$ and $\alpha=.88$ across all three waves (wave $1=0.70$; wave $2=.88$; wave $3=.85$ ), indicating acceptable to good internal consistency.

The CD-RISC-25 consists of 25 items, each rated on a 5-point Likert scale (Connor \& Davidson, 2003). The total score ranges from o to 100, with higher scores reflecting greater resilience. The CD-RISC-25 has good internal consistency $(\alpha=.89)$, high testretest reliability $(r=.87)$, and good convergent $(r=.83)$ and discriminant validity $(r=$ -.34). In the present study, Cronbach's alpha for the CD-RISC-25 ranged between $\alpha=.92$ and $\alpha=.94$ across all three waves (wave $1=0.92$; wave $2=0.94$; wave $3=0.94$ ), indicating good to excellent internal consistency.

\section{Procedure}

The CIR program process evaluation consisted of a time-series design that included three distinct waves of data collection conducted in October 2015, January 2016, and April 2016. Each wave of data collection was administered via CampusLabs, a web-based survey software. At each wave of data collection, prospective respondents received an email invitation to participate in an evaluation of the CIR program. This email invitation outlined the purpose of the evaluation, expectations of participants, a detailed description of the procedures involved, the risks and benefits associated with participation, and a list of on- and off-campus supports and services if students experienced distress because of their participation. After reviewing these details, prospective participants indicated their desire to participate by clicking on a generic web-link. Participants were then redirected to an anonymous web-based survey, which took approximately 15-20 minutes to complete.

\section{Results}

\section{Part One: Quantitative Analyses}

Combinations of descriptive and inferential statistical analyses were used to analyze the quantitative data. Of note, the anonymous nature of the survey rendered it impossible to discern whether students responded to one, two, or all waves of data collection, which 
introduced the possibility of repeated responses. Given the transient nature of occupancy in on-campus housing, however, the possibility of repeated measures was thought to provide the most naturalistic picture of students' mental health literacy and resilience (as well as physical presence) in on-campus housing at various points in the year. Thus, the potential for yielding repeated responses was considered a reasonable trade-off for obtaining a representative and realistic sample of the residence community over the course of an academic year.

Demographics. The collapsed sample was diverse in terms of age, gender, ethnicity, and academic level of study (undergraduate or graduate). Participants ranged in age from 17 to 40 years $(M=21.19, S D=3.98)$, with the majority of the sample $(85.9 \%)$ falling within the 17-to-24-year age range. The sample also had a female preponderance relative to the general residence population at $\mathrm{U}$ of $\mathrm{C}$ (64.4\% relative to approximately 51\%). Given that higher female to male response rates are typical of survey research (Sax, Gilmartin, \& Bryant, 2003), this finding was deemed consistent with similar research with post-secondary student populations (e.g., Pritchard et al., 2007). Participants were predominately Caucasian, although the sample contained a range of other ethnicities (e.g., Asian, African-American, Hispanic). Finally, undergraduate students comprised the majority of the sample (80.3\%), with graduate students comprising the other $19.7 \%$. Various areas of study were represented (irrespective of level of study), with the most prominent being arts, medicine, and engineering.

Total sample. No significant differences were observed in average group mental health literacy and resilience scores across the three time intervals. As a result, the three data waves were collapsed into a single sample. Descriptive statistics were run to obtain the average mental health literacy score (MHLS) and resilience (CD-RISC-25) scores of the total sample $(N=354)$, as well as the correlation between mental health literacy and resilience. Overall, scores on the MHLS ranged from 92 to $155(M=128.19, S D=12.47)$ and scores on the CD-RISC-25 ranged from 20 to $100(M=67.36, S D=14.98)$. Notably, these scores were considered somewhat lower than what is typically observed in university student populations (Connor \& Davidson, 2003), which suggests that students living in residence constitute a unique subpopulation within the larger student community and further highlights the need for residence-based mental health initiatives.

Despite there being no statistically significant changes in average levels of mental health literacy and resilience over time, a qualitative analysis of the distribution of MHLS and CD-RISC-25 scores at the three time points revealed notable changes in the variance of these variables as the year progressed. This finding holds interesting implications for the temporal sequencing of program delivery, highlighting the importance of providing mental health programming that coincides with peak stress periods of the year such as final exam time. Finally, there was no significant linear relationship between MHLS and CD-RISC-25 scores $(r=0.068, p>$.05) which suggests that mental health literacy and resilience play disparate roles in shaping student mental health and help-seeking behaviours and may need to be targeted separately.

Given the demographic diversity of the sample, a series of independent samples t-tests and one-way between-subjects ANOVAs were run to evaluate group level differences in resilience and mental health literacy relative to demographic variables, including gender, level of study, year of study, and international student status. Importantly, Bonferroni 
corrections were applied to all analyses to control for Type I error rates and preserve the reliability of findings.

Gender. An independent samples t-test was conducted to compare average MHLS scores between males and females. There was a significant difference in average MHLS scores between males and females, $t(343)=-6.677, p<0.001$, with males reporting lower MHLS scores than females. In contrast, an independent-samples t-test comparing gender differences in average CD-RISC-25 scores found no significant difference between males and females, $t(343)=1.986, p=0.048$, indicating that males and females are generally comparable in terms of their average level of resilience.

Level of study. Independent samples t-tests were conducted to compare average MHLS and CD-RISC-25 scores between undergraduate and graduate students. Overall, no significant differences were found between undergraduate and graduate students on the MHLS, $t(349)=1.995, p=0.047$, nor on the CD-RISC-25, $t(349)=-1.445, p=0.149$. These results suggest that undergraduate and graduate students are comparable in terms of their average levels of resilience and mental health literacy.

Year in program. One-way between-subjects ANOVAs were conducted to compare the average MHLS and CD-RISC-25 scores between years in program (i.e., 1, 2, 3, 4, or 5+) for the total sample only, as there were insufficient numbers to conduct separate ANOVAs for undergraduate and graduate students. Overall, no significant differences were found between year of study on the MHLS, $F(4,347)=1.130, p>.05$, nor on the CD-RISC-25, $F(4,347)=1.614, p>.05$. These results suggest that students in all years and levels of study are comparable in terms of their average levels of resilience and mental health literacy.

International student status. An independent samples t-test was conducted to compare average MHLS scores between international and domestic students. There was a significant difference in average MHLS scores between international and domestic students, $t(350)=-5.68, p<0.001$, with international students reporting lower MHLS scores than domestic students. In contrast, an independent-samples t-test comparing student status differences in average CD-RISC-25 scores found no significant difference between international and domestic students, $t(153.198)=1.257, p=0.211$, indicating that international students and domestic students are generally comparable in terms of their average level of resilience.

\section{Part Two: Qualitative Analyses}

Openness and barriers to accessing CIR counselling. In addition to the MHLS and CD-RISC-25, students were asked to answer several evaluator-constructed questions about their willingness to access CIR counselling services, their perceived barriers to accessing these services, and whether they had sought counselling services in the past. As can be seen from Table 2, the majority of students reported a willingness to seek residence-based counselling services if needed (40.9\% to 66.7\%), with willingness increasing throughout the school year. For those who answered "no" or "unsure" $(n=150)$, the most commonly cited barriers included (a) a perceived lack of need (25.3\%), (b) a lack of awareness of the program and/or the availability of services (20.7\%), (c) time constraints (8.7\%), (d) stigma (5.3\%), and (e) already accessing counselling services elsewhere (4.7\%). Finally, approximately one-third of the sample reported accessing counselling services in the past depending on the time point. 
Table 2. Openness to Accessing CIR Counselling and Previous Counselling Attendance as a Percentage of the Sample

\begin{tabular}{lccc}
\hline & $\begin{array}{c}\text { October } \\
2015 \\
(n=149)\end{array}$ & $\begin{array}{c}\text { January } \\
2016 \\
(n=130)\end{array}$ & $\begin{array}{c}\text { April } \\
2016 \\
(n=75)\end{array}$ \\
\hline Willingness to Seek Counselling in Residence & & & \\
$\quad$ Yes & 40.9 & 64.6 & 66.7 \\
No & 18.8 & 7.0 & 12.0 \\
$\quad$ Unsure & 40.3 & 28.5 & 21.3 \\
Sought Counselling Services in the Past & & & \\
$\quad$ Yes & 19.8 & 33.1 & 29.3 \\
No & 79.2 & 66.9 & 70.7 \\
\hline
\end{tabular}

Perceived needs pertaining to CIR programming. Students were also asked evaluator-constructed questions pertaining to the most desired mental health topics they would learn about through events and workshops. Topics that were of the greatest interest to students in October 2015 included depression, stress, anxiety, eating disorders, and how to help others. Topics that were of greatest interest to students in January 2016 included mental illness awareness, anxiety, and depression.

\section{Discussion}

The results indicate that mental health literacy and, in particular, stigma reduction are important elements of residence-based mental health programming. Furthermore, important differences in mental health literacy emerge between subpopulations within the residence-based student body. These findings support previous research that has illuminated the vital role of stigma, resilience, and mental health literacy in influencing helpseeking attitudes and behaviours (Eisenberg, Downs, Golberstein, \& Zivin, 2009; Sickel, Seacat, \& Nabors, 2014). A study conducted by Eisenberg, Downs, Golberstein, and Zivin (2009) found that personal stigma was higher among males, international students, and students from lower socio-economic statuses. In addition, higher personal stigma was associated with lower help-seeking behaviours. Interestingly, Sickel, Seacat, and Nabors (2014) found that stigma and resilience may be connected insofar that feelings of stigma inhibit coping strategies, following treatment plans, and self-efficacy. It is also plausible these elements may account for disproportionate utilization of residence-based mental health services among specific subpopulations, such as males (Dobmeier et al., 2011) and international students (Lu, Dear, Johnston, Wootton, \& Titov, 2014). Consequently, the following discussion will focus on locating the current findings within the literature on stigma, mental health literacy, resilience, and help-seeking pertaining to these two student subpopulations.

\section{International and Culturally Diverse Students}

The current evaluation found that domestic students exhibited significantly higher mental health literacy compared to international students. Corrigan, Druss, and Perlick 
(2014) reviewed the factors impacting stigma and the role of stigma in seeking and participating in mental health services and found that higher mental health literacy moderated stigma (i.e., increased mental health literacy decreases stigmatizing beliefs). More importantly, cultural relevance appeared to moderate the role of stigma in help-seeking and engagement with services (Corrigan et al., 2014). Conversely, Lu, Dear, Johnston, Wootton, and Titov (2014) used an online survey to assess Chinese-speaking international students' mental health concerns and barriers to help-seeking. The results indicated that international students cited several barriers to help-seeking, including cost/ financial concerns, having limited knowledge of available services, time constraints, the perception that symptoms were not severe enough to warrant treatment, language difficulties, and a lack of knowledge of symptoms. Furthermore, a study conducted by Hyun, Quinn, Madon, and Lustig (2007) surveyed 3,121 graduate students online at a university in the United States (551 were international students, approximately $18 \%$ of the sample). Overall, Hyun et al. (2007) found that international students exhibited lower knowledge, awareness, and utilization of on-campus counselling services compared to their domestic counterparts, despite the fact that the prevalence of mental health needs was equal between the two groups. Collectively, these findings suggest that compared to domestic students, international students may not be as aware of campus-based mental health services, and may not perceive available services to be culturally relevant or designed to meet their mental health needs.

\section{Gender}

In the current evaluation, an important finding that emerged was the significant difference in mental health literacy between male and female students. Previous research has investigated the relationship between mental health literacy and help-seeking attitudes and behaviours, and found mental health literacy to be a significant predictor of help-seeking intentions (Smith \& Shochet, 2011). Of particular interest to the current evaluation, a study conducted by Dobmeier et al. (2011) found that females demonstrated greater awareness of mental health problems overall, whereas males exhibited lower mental health literacy than females, as measured by ability to recognize the signs, symptoms, and risk factors associated with mental health problems. In another study, Vogel, Wester, Hammer, and Downing-Matibag (2013) used structural equation modelling with a sample of 216 male college students and found that men's experiences of gender roles were associated with an increased endorsement of stigmatization around mental health concerns, and a decreased willingness to refer friends and family members to seek help. Interestingly, males who endorsed greater restriction of affectionate behaviour between men also endorsed greater stigma (Vogel et al., 2013). As such, these studies provide further support for the current finding that males exhibited lower mental health literacy than their female counterparts, and that stigma may be an important contributor to males' lower mental health literacy. Given our findings that male and international students reported lower levels of mental health literacy compared to their female and domestic counterparts, future programming efforts may wish to target male mental health literacy specifically to enhance help-seeking attitudes and behaviours within this population. 


\section{Limitations}

The current evaluation presents a number of limitations worth noting. The fact that the evaluation instrument was not designed to track intra-individual change over time eliminated the evaluators' abilities to account for repeated respondents, thereby rendering it impossible to deem each wave of data as independent. Also, the current evaluation did not assess the types of stressors that each group faced, and how they effectively coped with each stressor. Given that the various subpopulations within residence may have different mental health needs and worldviews, this information would have been valuable in informing future directions for CIR programming. In addition, the current evaluation is subject to response bias in that those who chose to complete the survey may be different in terms of mental health literacy and resilience from those who chose not to participate in the evaluation. Finally, the finding that international students exhibit significantly lower mental health literacy than domestic students should be interpreted with caution. The MHLS privileges a Western worldview of mental health literacy and, more broadly, what it means to be knowledgeable and aware of mental health challenges and relevant supports. As such, it is plausible that international students hold diverse understandings of mental illness and mental health and, by extension, mental health literacy. Given that the MHLS measures literacy from a Western perspective, the differences between international and domestic students may be more indicative of the need to investigate and explore culturally diverse understandings of mental health literacy. However, in weighing the identified limitations, the findings of the current evaluation provide valuable information for understanding the target population of residence-based students at the University of Calgary, and offers insight into planning and designing future CIR programming that will be of benefit to residence students.

\section{Conclusions}

In the current evaluation, male and international students reported lower levels of mental health literacy (e.g., awareness, knowledge, attitudes associated with stigma) compared to their counterparts. These findings indicate that post-secondary mental health literacy programming, including stigma reduction efforts, should be designed for and tailored to specific subpopulations within student residences (Eisenberg, Downs, Golberstein, \& Zivin, 2009). Most importantly, stigma reduction efforts should be targeted to those subpopulations who exhibit higher levels of stigma, as targeting these groups may enhance attitudes that foster greater help-seeking. With specific attention toward international students, residence-based mental health services should be tailored to the diverse worldviews of international students. It is also important to note that this research highlights the possibility that current mental health literacy instruments, which focus exclusively on Western views and perspectives of mental health, may not capture culturally diverse perspectives on mental health and well-being. As such, future research and evaluation may wish to investigate culturally diverse understandings of mental health and mental health literacy to obtain an accurate representation of this construct among international students.

Given that previous research has established the important role of mental health literacy in help-seeking attitudes and behaviours, and that the findings from the current evalu- 
ation support this linkage, it is recommended that future CIR programming be tailored according to the attitudes, behaviours, and unique barriers present within different subpopulations of students living in residence. This would include targeting workshops and programming to specific subpopulations (e.g., males, international students) and toward peak periods of stress during the academic year. In addition, CIR program developers may optimize international and male student access and utilization of residence-based services by tailoring programming according to culturally relevant worldviews and the specific beliefs interfering with mental health literacy acquisition within these subpopulations, respectively. In addition, Smith and Schohet (2011) recommend that mental health literacy programs may benefit from addressing the following elements: (a) enhancing target populations' knowledge about the benefits and usefulness of psychosocial interventions (i.e., counselling, therapy), (b) emphasizing the availability of cost-effective or free services, and (c) stressing the ethic of confidentiality in mental health professions. The need for these elements is echoed in the current evaluation findings, in that respondents generally lacked awareness of the availability of mental health services, perceived mental health services as being unhelpful or ineffectual, and expressed stigma as a barrier to help-seeking. As such, CIR programming would benefit from continuing to incorporate education and awareness around these barriers into future mental health literacy programming.

In an effort to incorporate the findings of this evaluation into future mental health literacy programming, CIR programming staff have shifted their efforts to meet the specific needs of the student population as indicated in the evaluation findings. In September 2016, residence-based counselling services expanded its scope by adding a second office in the graduate residence hall for counselling appointments and intake meetings. Given that $47 \%$ of students living in the graduate hall identify as international students (comprising $19.2 \%$ of all self-identified international students living in residence), CIR program supervisors are devoting greater attention to supporting students in the graduate residence. Preliminary steps have also been taken to explore pathways to increasing mental health awareness and programming tailored toward males and international students in all residence buildings. For instance, collaboration with campus services and student clubs at the University of Calgary, such as the Centre for International Students and Study Abroad or the ManUp for Mental Health program, could help advance efforts to increase mental health literacy and resilience levels in residence students. Finally, in moving forward, the CIR program aspires to remain accountable to the mental health needs and preferences of residence students, and will continue to focus its efforts on improving those aspects of CIR programming that are identified through ongoing, routine program evaluation."

\section{Acknowledgement}

This project was supplied in part from an Advanced Education Mental Health Grant.

\section{References}

American College Health Association. (2013). American College Health AssociationNational College Health Assessment II. Canadian reference group executive summary spring 2013. Hanover, MD: American College Health Association. Retrieved from http://campusmentalhealth.ca/wp-content/uploads/2015/05/Canadian-S13-Ref-GrpExecutive-Summary2.pdf 
Arnett, J. J. (2000). Emerging adulthood: A theory of development from the late teens through the twenties. American Psychologist, 55(5), 469-480. http://dx.doi. org/10.1037/0003-066X.55.5.469

Beatie, B. E., Stewart, D. W., \& Walker, J. R. (2016). A moderator analysis of the relationship between mental health help-seeking and behaviours among young adults. Canadian Journal of Counselling and Psychotherapy, 5O(3), 290-314. Retrieved from http://cjc-rcc.ucalgary.ca/cjc/index.php/rcc/article/view/2871/pdf_1

Blanco, C., Okuda, M., Wright, C., Hasin, D. S., Grant, B. F., Liu, S., \& Olfson, M. (2008). Mental health of college students and their non-college attending peers: Results from the national epidemiologic study on alcohol and related conditions. Archives of General Psychiatry, 65(12), 1429-1437. doi:10.1001/archpsyc.65.12.1429

Connor, K. M., \& Davidson, J. R. (2003). Development of a new resilience scale: The Connor-Davidson Resilience Scale (CD-RISC). Depression and Anxiety, 18(2), 76-82. doi:10.1002/da.10113

Corrigan, P. W., Druss, B. G., \& Perlick, D. A. (2014). The impact of mental illness stigma on seeking and participating in mental health care. Psychological Science in the Public Interest, 15(2), 37-70. https://doi.org/10.1177/1529100614531398

Coskun, Y.D., Garipagaoglu, C., \&Tosun, U.(2014). Analysis of the relationship between the resiliency level and problem-solving skills of university students. Procedia-Social and Behavioral Sciences, 114, 673-680. https://doi.org/10.1016/j.sbspro.2013.12.766

DeRosier, M. E., Frank, E., Schwartz, V., \& Leary, K. A. (2013). The potential role of resilience education for preventing mental health problems for college students. Psychiatric Annals, 43(12), 538-544. doi:10.3928/00485713-20131206-05

Dobmeier, R. J., Hernandez, T. J., Barrell, R. J., Burke, D. J., Hanna, C. J., Luce, D. J., . . . \& Siclare, M. (2011). Student knowledge of signs, risk factors, and resources for depression, anxiety, sleep disorders, and other mental health problems on campus. New York Journal of Student Affairs, 11(1), 103-122. Retrieved from http://journals.canisius. edu/index.php/CSPANY/article/view/122

Eisenberg, D., Downs, M. F., Golberstein, E., \& Zivin, K. (2009). Stigma and help seeking for mental health among college students. Medical Care Research and Review, 66(5), 522-541. doi:10.1177/1077558709335173

Eisenberg, D., Golberstein, E., \& Gollust, S. E. (2007). Help-seeking and access to mental health care in a university student population. Medical Care, 45(7), 594-601. doi:10.1097/MLR.obo13e31803bb4c1

Eisenberg, D., Hunt, J., Speer, N., \& Zivin, K. (2011). Mental health service utilization among college students in the United States. The Journal of Nervous and Mental Disease, 199(5), 301-308. doi:10.1097/NMD.obo13e3182175123

Flatt, A. K. (2013). A suffering generation: Six factors contributing to the mental health crisis in North American higher education. The College Quarterly, 16(1), 1-17. Retrieved from https://files.eric.ed.gov/fulltext/EJ1016492.pdf

Goh, A. M. Y., \& Chiu, E. (2009). Campus mental health: Are we doing enough? AsiaPacific Psychiatry, 1(2), 58-63. doi:10.1111/j.1758-5872.2009.00017.x 
Gulliver, A., Griffiths, K. M., \& Christensen, H. (2010). Perceived barriers and facilitators to mental health help-seeking in young people: A systematic review. $B M C$ Psychiatry, 10(113), 1-9. https://doi.org/10.1186/1471-244X-10-113

Harrison, S. H. (2013). Our forgotten students: The mental health of residence hall paraprofessionals (Unpublished doctoral dissertation). Texas Tech University, Lubbock, Texas.

Hartley, M. T. (2012). Assessing and promoting resilience: An additional tool to address the increasing number of college students with psychological problems. Journal of College Counselling, 15(1), 37-51. doi:10.1002/j.2161-1882.2012.00004.X

Heck E., Jaworska, N., DeSomma, E., Dhoopar A. S., MacMaster F. P., Dewey, D., \& MacQueen, G. (2014). A survey of mental health services at post-secondary institutions in Alberta. The Canadian Journal of Psychiatry, 59(5), 250-258. doi:10.1177/070674371405900504

Hyun, J., Quinn, B., Madon, T., \& Lustig, S. (2007). Mental health need, awareness, and use of counselling services among international graduate students. Journal of American College Health, 56(2), 109-118. https://doi.org//10.3200/JACH.56.2.109-118

Johnson, M. L., Taasoobshirazi, G., Kestler, J. L., \& Cordova, J. R. (2015). Models and messengers of resilience: A theoretical model of college students' resilience, regulatory strategy use, and academic achievement. Educational Psychology, 35(7), 869-885. doi:1 $0.1080 / 01443410.2014 .893560$

Kirsch, D. J., Pinder-Amaker, S. L., Morse, C., Ellison, M. L., Doerfler, L. A., \& Riba, M. B. (2014). Population-based initiatives in college mental health: Students helping students to overcome obstacles. Current Psychiatry Reports, 16(525), 1-8. doi:10.1007/ s11920-014-0525-1

Klibert, J., Lamis, D. A., Collins, W., Smalley, K. B., Warren, J. C., Yancey, C. T., \& Winterowd, C. (2014). Resilience mediates the relations between perfectionism and college student distress. Journal of Counseling and Development, 92(1), 75-82. doi:10.1002/ j.1556-6676.2014.00132.x

Lu, S. H., Dear, B. F., Johnston, L., Wootton, B. M., \& Titov, N. (2014). An internet survey of emotional health, treatment seeking and barriers to accessing mental health treatment among Chinese-speaking international students in Australia. Counselling Psychology Quarterly, 27(1), 96-108. https://doi.org/10.1080/09515070.2013.824408

O’Connor, M., \& Casey, L. (2015). The Mental Health Literacy Scale (MHLS): A new scale-based measure of mental health literacy. Psychiatry Research, 229(1), 511-516. doi:10.1016/j.psychres.2015.05.064

Potvin-Boucher, J., Szumilas, M., Sheikh, T., \& Kutcher, S. (2010). Transitions: A mental health literacy program for postsecondary students. The Journal of College Student Development, 51(6), 723-727. http://dix.doi.org/10.1353/csd.2010.0014

Pritchard, M. E., Wilson, G. S., \& Yamnitz, B. (2007). What predicts adjustment among college students? A longitudinal panel study. Journal of American College Health, 56(1), 15-21. doi:10.3200/JACH.56.1.15-22 
Robinson, A. M., Jubenville, T. M., Renny, K., \& Cairns, S. L. (2016). Academic and mental health needs of students on a Canadian campus. Canadian Journal of Counselling and Psychotherapy, 5O(2), 108-123. Retrieved from http://cjc-rcc.ucalgary.ca/cjc/index. $\mathrm{php} / \mathrm{rcc} / \mathrm{article} / \mathrm{view} / 2848 / \mathrm{pdf}$

Saunders, R. P., Evans, M. H., \& Joshi, P. (2005). Developing a process-evaluation plan for assessing health promotion program implementation: A how-to guide. Health Promotion Practice, 6(2), 134-147. https://doi.org/10.1177/1524839904273387

Sax, L. J., Gilmartin, S. K., \& Bryant, A. N. (2003). Assessing response rates and nonresponse bias in web and paper surveys. Research in Higher Education, 44(4), 409432. https://doi.org/10.1023/A:1024232915870

Sickel, A. E., Seacat, J. D., \& Nabors, N. A. (2014). Mental health stigma update: A review of consequences. Advances in Mental Health, 12(3), 202-215. https://doi.org/10 $.1080 / 18374905.2014 .11081898$

Smith, C. L., \& Shochet, I. M. (2011). The impact of mental health literacy on help-seeking intentions: Results of a pilot study with first year psychology students. International Journal of Mental Health Promotion, 13(2), 14-20. https://doi.org/10.10 80/14623730.2011.9715652

Vogel, D. L., Wester, S. R., Hammer, J. H., \& Downing-Matibag, T. M. (2013). Referring men to seek help: The influence of gender role conflict and stigma. Psychology of Men \& Masculinity, 15(1), 60-67. http://dx.doi.org/10.1037/a0031761

Yorgason, J. B., Linville, D., \& Zitzman, B. (2008). Mental health among college students: Do those who need services know about and use them? Journal of American College Health, 57(2), 173-182. htpps://doi.org/10.3200/JACH.57.2.173-182

\section{Contact Information}

Tiffany A. Beks

Werklund School of Education

University of Calgary

tiffany.beks@ucalgary.ca

Tiffany A. Beks is completing a PhD in Counselling Psychology at the University of Calgary in Alberta, Canada. Previously, Tiffany conducted research related to counselling outcomes, depression, anxiety, disordered eating, trauma, and family violence at the Calgary Counselling Centre. Tiffany has since turned her research focus to military families. Her primary research focuses on barriers to access and utilization of mental health services among family members of military personnel. Tiffany also conducts research in the area of post-secondary counselling, program evaluation, and mental health.

Sharon L. Cairns completed her education at the Universities of Winnipeg and Manitoba in psychology and clinical psychology. She worked for 11 years in post-secondary counselling with particular interests in interpersonal trauma, disordered eating, procrastination, perfectionism, strategies for academic success, and program evaluation. She then trans- 
ferred to the Counselling Psychology Program at the University of Calgary where she is an associate professor. Research interests are post-secondary counselling, program evaluation, trauma, resilience, and mental health.

Serena. L. Smygwaty is a recent graduate from the Master of Science program in School and Applied Child Psychology at the University of Calgary in Calgary, Alberta. She is currently pursuing registration as a psychologist practitioner and is working as a psychologist intern for a local school board. While her current research interests surround psychoeducational assessment techniques and interventions, she also has an interest in campus-based mental health initiatives.

Olga A. L. Miranda Osorio obtained her BA in Psychology and Sociology from the University of Alberta. Olga worked as Residence Life Coordinator for four years in Calgary and Toronto, and has a special interest in supporting international students in post-secondary settings. Olga's contributions to the implementation and development of the Counsellorin-Residence program stem as well from her interest in mental health awareness and support for college and university students in Canada. She is currently working with the University of British Columbia at the International Student Development Department.

Sheldon J. Hill is a current student at Western University, completing his MA in Counselling Psychology. With ample experience of working in student affairs and higher education, his research interests lie in the intersection of mental health and post-secondary support and policies. Research that informs the direction of new and existing programs and initiatives aimed toward supporting the mental well-being of students is the focus of his thesis, bridging that gap between research and administrative implementation. 